\title{
A Study To Evaluate The Effectiveness Of Self Instructional Module On Knowledge Regarding Revised National Tuberculosis Control Programme For The Female Health Workers Of Selected Primary Health Centres Of Tumkur District, Karnataka
}

\author{
Mr Swamy Pgn ${ }^{1}$, Mrs Shilpa Pm² \\ Assistant Professor, Sumandeep Nursing College, Piparia, Gujarat, India. \\ Assistant Professor, Nrupur Institute of Nursing Sciences \& Research, Vadodara, Gujarat, India.
}

\begin{abstract}
Tuberculosis is one of the most common infectious diseases and serious public health problem in the World. Objectives of National Tuberculosis Programme (NTP) range from reducing the TB burden \& eradicating the disease globally with the efforts of health workers who play a vital role in tuberculosis control. Objectives: To evaluate the effectiveness of self instructional module (SIM) on knowledge regarding revised national tuberculosis control programme \& to find an association between the pre-test level of knowledge with selected socio-demographic variables of female health workers. Materials and methods: The investigator used pre experimental research (one group pre-test post-test design). Purposive sampling technique was used to assess the knowledge of 30 female health workers in selected primary health centres of Tumkur district. Self administered knowledge questionnaire was used to assess the knowledge of female health workers. The conceptual framework used for this study was based on Patrecia Benner's Novice to expert model. The data was analysed by using descriptive and inferential statistics. Student T test was used to evaluate the effectiveness of SIM. Results: It was evident that the obtained T value 23.716 is greater than the table value at 0.05 (2.021) level of significance. Therefore " $T$ " value is found to be significant. It indicates that there is a significant difference between pre-test and post-test knowledge of female health workers regarding revised national tuberculosis control programme. Conclusion: Hence SIM is considered as one of the effective teaching strategy in imparting knowledge regarding RNTCP among female health workers.

Keywords: female health workers, SIM and RNTCP
\end{abstract}

\section{Introduction}

Revised National Tuberculosis Control Programme initiative in 1993 and stop TB strategy by W.H.O has featured high on the TB control by alleviating poverty and strengthen health systems in TB endemic countries. Increasing national political commitment to control TB and intensified efforts in endemic countries has been supported greatly by United Nations Organisations, UNICEF and other partners. As a result, efforts to achieve high coverage with TB interventions are now underway in most TB-endemic countries of world, especially South East Asia Region (SEAR) countries where burden of TB is greatest. As a result, efforts to achieve high coverage with tuberculosis interventions are now under way in most TB endemic countries of the world. Principal objectives of health workers are to shorten the duration of the illness and cure it; to prevent the illness from becoming severe; to avoid death and to prevent further transmission. They play vital role in making proper diagnosis; starting treatment with anti tuberculosis drugs; supervising treatment, and ensuring the first dose of anti tuberculosis drug is administered; Keeping confidentiality; Being alert to the possibility that clients may have sought and received anti tuberculosis treatment from other sources.

\section{Need for the Study}

India is the highest TB burden country in world despite the fact that the causative organism was discovered more than 100 years ago, highly effective drugs and vaccines are available making TB a preventable and curable disease. National Health Policy 2002 envisaged a goal of reducing mortality to $50 \%$ by 2010 and efficient morbidity control. Augmentation of case finding activities through quality sputum microscopy is done, there by achieving reduction of TB mortality and morbidity to meet the overall objectives of reducing poverty.

One way to achieve the above mentioned effort is by assessing the knowledge of health workers, who play a vital role in tuberculosis control. This is because they spend most of their time with the people in villages and they know the severity of disease and the best way to handle tuberculosis. According to World Health Organisation global report march 2009, there were nearly 9.2 million new cases and 1.9 million deaths were reported due to TB, and over $90 \%$ of these occurred in low and middle income countries where TB is one of the 
leading cause of adult mortality, ranking $3^{\text {rd }}$ as a cause of death among those aged 15-49 years. Out of 22 high burden countries (accounting for $80 \%$ of global TB burden) five are in SEAR including India.

India accounting for $1 / 5^{\text {th }}$ of global incidence, $2 / 3^{\text {rd }}$ of cases in South East Asia Region (SEAR) and $17^{\text {th }}$ among 22 high burden countries in terms of TB incidence rate. Prevalence of TB is about 299/lakh population as per the WHO 2008 global TB report. Everyday more than 5000 people develop TB disease and nearly 1000 people die of TB that is 2 deaths every 3 minutes. As per WHO global report 2008, nearly 322,000 people in India died of TB. The magnitude from the state of Karnataka in 2008 shows that 419,401 numbers of suspects examined, 41,530 number of smear positive patients were diagnosed and 66,159 number of patients registered for treatment. It has been observed that the incidence of TB increases with the poor life style standards and thus transmits the disease.

\section{Statement of the study}

"A study to evaluate the effectiveness of self instructional module on knowledge regarding revised national tuberculosis control programme for the female health workers of selected primary health centres at Tumkur district, Karnataka".

\section{Objectives of the study}

$>$ To assess the knowledge of female health workers regarding revised national tuberculosis control programme.

$>$ To evaluate the effectiveness of self instructional module on knowledge regarding revised national tuberculosis control programme among female health workers.

$>$ To find an association between the pre-test level of knowledge with selected socio-demographic variables of female health workers.

\section{Operational Definitions:}

Effectiveness: It refers to gain in knowledge regarding revised national tuberculosis control programme among female health workers as determined by significant difference between pre-test and post-test scores.

Self instructional module: In this study, self instructional module refers to a visual teaching aid that consists of information regarding incidence, prevalence, WHO standards of TB care and treatment, stop TB strategies.

Knowledge: In this study, knowledge refers to correct response given by female health workers regarding Revised National Tuberculosis Control Programme as elicited through self administered knowledge questionnaire.

\section{Hypothesis:}

H1- There is a significant difference between Pre-test and Post-test knowledge scores of female health workers regarding revised national tuberculosis control programme.

H2- There is a significant association between the pre-test level of knowledge of female health workers with selected socio-demographic variables.

\section{Assumptions}

\section{The study assumes that}

- Female health workers will have limited knowledge on revised national tuberculosis control programme.

- Self instructional module is one of the best teaching strategies in imparting knowledge regarding revised national tuberculosis control programme for the female health workers. 


\section{Conceptual Framework}

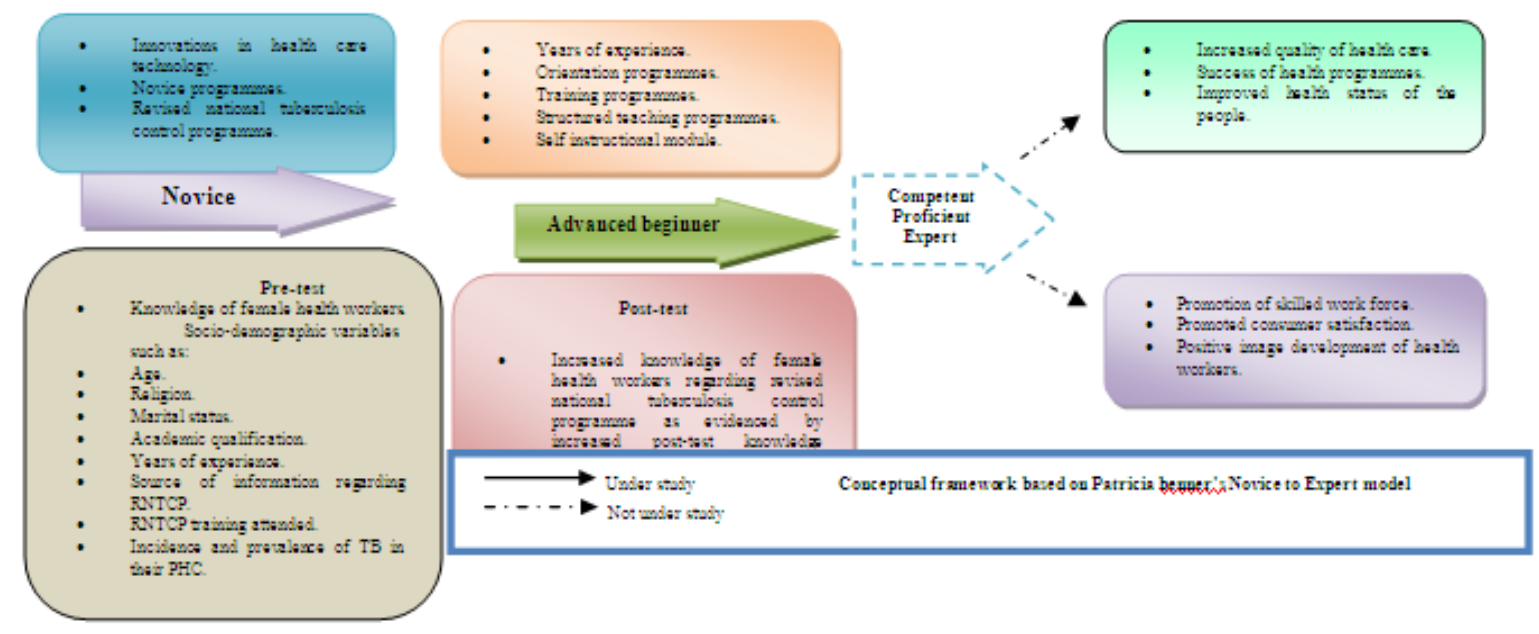

\section{Research Methodology}

Research methodology is a way to solve the research problem systematically. It deals with defining the problem, formulation of hypothesis, methods adopted for data collection and statistical techniques used for analysing the data with logical reason behind it.

Research approach: Evaluative approach

Research design: Pre-experimental one group pre-test and post-test design

Variables under study

Independent variable: Self instructional module.

Dependent variable: Knowledge score of female health workers.

Setting of the study: Selected P.H.C's at Tumkur district includes Kyatasandra, Shettyhalli, Mallasandra, Ramagondanahalli.

Population: Female health workers working in P.H.C's of Tumkur.

Sample and sampling technique

Sample: 50 female health workers. Non-probability purposive sampling technique was used to select the female health workers.

\section{Criteria for sample selection}

Inclusive criteria

1. Female health workers of selected Primary Health Centres of Tumkur District.

2. Female health workers who can read and write Kannada.

Exclusive criteria

1. Female health workers who are not willing to participate in the study.

2. Female health workers who are not available at the time of data collection.

\section{Data collection method}

Self administered knowledge questionnaire was used to determine the knowledge of female health workers regarding RNTCP. The following steps were adopted in the development of the tool: Review of literature, Discussion with nursing scholars and experts from the field of community medicine, Development of a blueprint, Construction of a self administered knowledge questionnaire, Content validity, Pre-testing of the tool, Reliability.

\section{Development of the tool:}

Self administered knowledge questionnaire was developed by the investigator for assessing the knowledge of female health workers regarding RNTCP. The tool was developed after review of literature on relevant topics and in consultation with subject experts.

\section{Description of tool:}

Self administered knowledge questionnaire was used to assess the knowledge of female health workers regarding revised national tuberculosis control programme. It consisted of two parts: 
Part I Socio-demographic data with 08 items for obtaining information about selected factors such as age, religion, marital status, academic qualification, source of health information regarding RNTCP, professional experience in years, RNTCP training attended, and incidence and prevalence of TB in the PHC.

Part II Multiple choice questions on knowledge of female health workers regarding RNTCP. Total items were 30 , with total score of 30 .

The scoring scale consists of one correct option for the all multiple choice items. There were a total of 30 items. Score ' 1 ' is given for each correct response and ' 0 'for incorrect response. The scores range from a minimum of ' 0 'to a maximum score of 30 .

The knowledge level has been arbitrarily divided into three categories.

- Adequate knowledge: $>75 \%$

- Moderately adequate knowledge: $50 \%-75 \%$

- Inadequate knowledge: $<50 \%$

\section{Data Analysis}

SECTION A : Distribution of female health workers based on socio demographic variables. Frequency and percentage distribution of female health workers based on socio-demographic variables. $\mathbf{N}=\mathbf{5 0}$

\begin{tabular}{|c|c|c|c|}
\hline \multicolumn{2}{|c|}{ variables } & \multirow{2}{*}{\begin{tabular}{|l} 
Frequency \\
17 \\
14 \\
19
\end{tabular}} & \multirow{2}{*}{\begin{tabular}{|l} 
Percentage (\%) \\
34.0 \\
28.0 \\
38.0
\end{tabular}} \\
\hline $\begin{array}{l}\text { 1. } \\
\text { a. } \\
\text { b. } \\
\text { c. } \\
\text { d. }\end{array}$ & $\begin{array}{l}\text { Age } \\
21-30 \text { years } \\
31-40 \text { years } \\
41-50 \text { years } \\
41-50 \text { years }\end{array}$ & & \\
\hline $\begin{array}{l}2 . \\
\text { a. } \\
\text { b. }\end{array}$ & $\begin{array}{l}\text { Religion } \\
\text { Hindu } \\
\text { Muslim }\end{array}$ & $\begin{array}{l}39 \\
11\end{array}$ & $\begin{array}{l}78.0 \\
22.0\end{array}$ \\
\hline $\begin{array}{l}3 . \\
\text { a. } \\
\text { b. }\end{array}$ & $\begin{array}{l}\text { Marital status } \\
\text { Married } \\
\text { Unmarried }\end{array}$ & $\begin{array}{l}44 \\
6\end{array}$ & $\begin{array}{l}88.0 \\
12.0\end{array}$ \\
\hline $\begin{array}{l}4 . \\
\text { a. } \\
\text { b. }\end{array}$ & $\begin{array}{l}\text { Academic qualification } \\
\text { SSLC } \\
\text { PUC }\end{array}$ & $\begin{array}{l}39 \\
11\end{array}$ & $\begin{array}{l}78.0 \\
22.0\end{array}$ \\
\hline $\begin{array}{l}5 . \\
\text { a. } \\
\text { b. } \\
\text { c. }\end{array}$ & $\begin{array}{l}\text { Source of information } \\
\text { Departmental pamphlet } \\
\text { IEC programme } \\
\text { Mass media }\end{array}$ & $\begin{array}{l}35 \\
9 \\
6\end{array}$ & $\begin{array}{l}70.0 \\
18.0 \\
12.0\end{array}$ \\
\hline $\begin{array}{l}\text { 6. } \\
\text { a. } \\
\text { b. } \\
\text { c. }\end{array}$ & $\begin{array}{l}\text { Years of experience } \\
0-10 \text { years } \\
11-20 \text { years } \\
21-30 \text { years }\end{array}$ & $\begin{array}{l}18 \\
30 \\
2\end{array}$ & $\begin{array}{l}36.0 \\
60.0 \\
4.0\end{array}$ \\
\hline $\begin{array}{l}7 . \\
\text { a. } \\
\text { b. }\end{array}$ & $\begin{array}{l}\text { RNTCP training attended } \\
\text { Yes } \\
\text { No }\end{array}$ & $\begin{array}{l}33 \\
17\end{array}$ & $\begin{array}{l}66.0 \\
34.0\end{array}$ \\
\hline $\begin{array}{l}8 . \\
\text { a. } \\
\text { b. } \\
\text { c. }\end{array}$ & $\begin{array}{l}\text { Incidence and prevalence of } \mathbf{T B} \text { in the } \mathbf{P H C} \\
\text { mild } \\
\text { moderate } \\
\text { severe }\end{array}$ & $\begin{array}{l}12 \\
17 \\
21\end{array}$ & $\begin{array}{l}24.0 \\
34.0 \\
42.0\end{array}$ \\
\hline
\end{tabular}

Majority of female health workers $19(38 \%)$ are in between the age group of 41-50 years. 17(34\%) of them are in between 21-30 years and only 14(28\%) are in between the age group of 31-40 years. 39(78\%) of the female health workers belongs to Hindu and only $11(22 \%)$ female health workers belongs to Muslim religion. $44(88 \%)$ of female health workers are married where as only $12 \%$ of female health workers are unmarried. About $39(78 \%)$ female health workers have studied up to SSLC and $11(22 \%)$ female health workers have completed their PUC. $35(70 \%)$ female health workers have got information about RNTCP through departmental pamphlet, $9(18 \%)$ female health workers gained knowledge through IEC programme whereas only $6(12 \%)$ female health workers accessed information through Mass media. $30(60 \%)$ female health workers have experience of 11-20 years, about 18 (36\%) female health workers have $0-10$ years of experience and only 2 (4\%) female health workers have experience in between $21-30$ years. $33(66 \%)$ female health workers have attended RNTCP training programme where as about 17 (34\%) female health workers have not attended RNTCP training programme. Incidence and prevalence of TB is severe in $21(42 \%)$ PHC's, moderate in 17 (34\%) PHC's and mild in 12 (24\%) PHC's. 
Table 16: comparison of pre-test and post-test knowledge scores of female health workers regarding revised national tuberculosis control programme.

$\mathbf{t}_{(49,0.05)}=\mathbf{2 . 0 2 1} \mathbf{N}=\mathbf{5 0}$

\begin{tabular}{|l|l|l|l|l|l|l|l|l|}
\hline \multirow{2}{*}{ Knowledge aspects } & \multicolumn{2}{l|}{ pretest } & \multicolumn{2}{l|}{ Post test } & \multicolumn{2}{l|}{ Inference } \\
\cline { 2 - 9 } & Mean & Mean \% & Std. Deviation & Mean & Mean \% & SD & \\
\hline Introduction, Incidence and prevalence of TB & 2.90 & 48.33 & 0.953 & 4.60 & 76.66 & 0.969 & 9.749 & Significant \\
\hline Aims and objectives of TB & 0.40 & 40 & 0.495 & 0.76 & 76 & 0.431 & 4.257 & Significant \\
\hline Host factors of TB & 1.72 & 43 & 0.904 & 3.06 & 76.5 & 0.740 & 9.454 & Significant \\
\hline Clinical features and diagnosis of TB & 1.58 & 39.5 & 1.090 & 3.12 & 78 & 0.773 & 8.836 & Significant \\
\hline Control measures of TB & 2.48 & 41.33 & 0.863 & 4.68 & 78 & 0.819 & 14.058 & Significant \\
\hline Side effects of TB drugs & 0.80 & 40 & 0.700 & 1.56 & 78 & 0.541 & 6.014 & Significant \\
\hline Protective and preventive measures of TB & 2.90 & 41.42 & 1.374 & 5.36 & 76.57 & 0.898 & 12.805 & Significant \\
\hline Overall knowledge scores & 12.78 & 42.6 & 3.112 & 23.14 & 77.13 & 2.499 & 23.716 & Significant \\
\hline
\end{tabular}

From the above table it is evident that the obtained' value 23.716 is greater than the table value at 0.05 (2.021) level of significance. Therefore " $t$ " value is found to be significant. It indicates that there is a significant difference between pre-test and post-test knowledge of female health workers regarding revised national tuberculosis control programme.

Table 17: Association between pre-test knowledge scores of female health workers with selected sociodemographic variables $\mathrm{N}=\mathbf{5 0}$

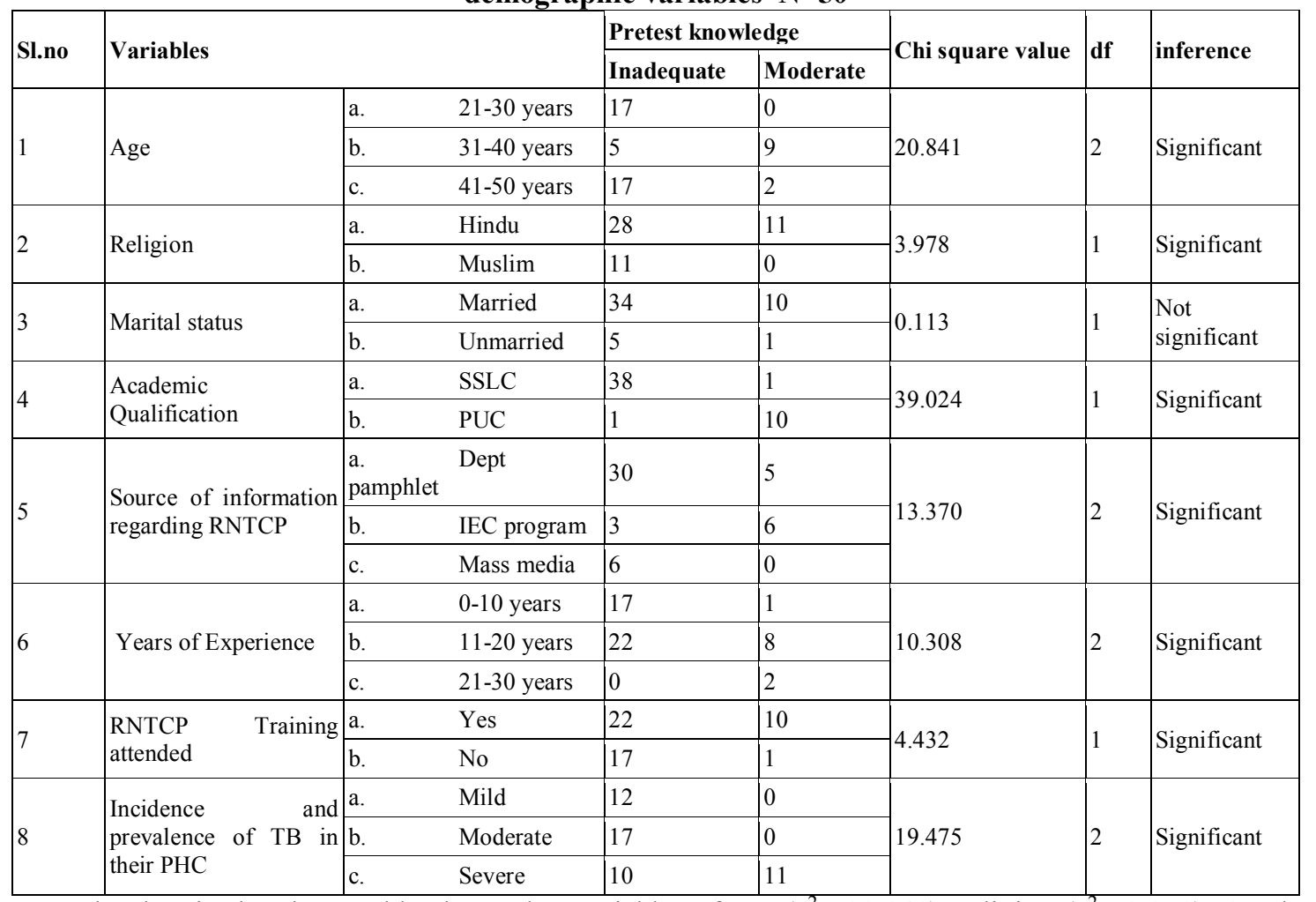

The data in the above table shows that variables of age $\left(\chi^{2}=20.841\right)$, religion $\left(\chi^{2}=3.978\right)$, Academic qualification $\left(\chi^{2}=39.024\right)$, source of information regarding RNTCP $\left(\chi^{2}=13.370\right)$, years of experience $\left(\chi^{2}=\right.$ 10.308), RNTCP training attended $\left(\chi^{2}=4.432\right)$, incidence and prevalence of TB in their PHC $\left(\chi^{2}=19.475\right)$ were found to be significant at 0.05 level, only marital status $\left(\chi^{2}=0.113\right)$ was not significant at 0.05 level.

\section{Conclusion}

The overall findings of the study shown that female health workers were having inadequate knowledge on RNTCP. The gain in mean knowledge score after administration of SIM is statistically significant at 0.05 levels. It has proved that SIM is an effective method in improving the knowledge of female health workers. Government authorities must provide in-service education and they should encourage female health workers and other health care personnel for the same. 
SIM prepared by the investigator for the study can also be used as a reference for teaching to other personnel. The present study in short gave the researcher a new experience, a chance to widen the knowledge and a venue to interact with female health workers. The constant encouragement and guidance of the guide, cooperation of the health department authorities and female health workers contributed to the fruitful completion of the study.

\section{References}

[1]. WHO global TB report, 2009 march. Available from: WHO website.

[2]. Central TB division.2009; Directorate of general of health services; ministry of health and family welfare; http://www.tbcindia.org

[3]. Revised national tuberculosis control programme. http:// www.tbcindia.org

[4]. K.Park, Text book of preventive and social medicine; $22^{\text {nd }}$ edition February 2009; Revised National Tuberculosis Control Programme.

[5]. Mahendra Panda and Mohapatra A; Tuberculosis control- An overview in India; Journal of human ecology. 